\title{
Helicobacter pylori infection in family members of patients with gastroduodenal symptoms. A cross-sectional analytical study
}

\author{
Ayse Palanduz', Levent Erdem", Birsen Durmaz Cetin"', Nuran Gülgün Ozcan'v \\ Istanbul University, Istanbul Bilim University and Koc University, Istanbul, Turkey
}

'MD. Associate Professor, Department of Family Medicine, Istanbul University, Istanbul Faculty of Medicine, Istanbul, Turkey.

Dorcid.org/0000-0002-9376-4039

"MD. Professor, Department of

Gastroenterohepatology, Istanbul Bilim

University Faculty of Medicine, Istanbul, Turkey.

Dorcid.org/0000-0002-7737-2764

'"MD. Professor, Department of Infectious

Diseases and Clinical Microbiology, Koc

University Faculty of Medicine, Istanbul, Turkey.

Dorcid.org//0000-0002-0745-393X

"MSc. Biologist, Ministry of Health, Second

Public Health Laboratory, Istanbul, Turkey.

Dorcid.org/0000-0002-5856-7910

\section{KEY WORDS:}

Helicobacter pylori.

Disease transmission, infectious.

Family.

Parents.

Siblings.

\begin{abstract}
BACKGROUND: Primary Helicobacter pylori (H. pylori) infection is acquired predominantly in childhood in the family setting. We aimed to investigate the presence of intrafamilial concurrent $H$. pylori infection. DESIGN AND SETTING: Cross-sectional analytical study with a control group, conducted in a tertiary care hospital. METHODS: Fifty adult patients with gastroduodenal symptoms who underwent gastroscopy (index parents), their spouses and their children were enrolled in the study. Blood samples were collected from all of the study subjects to test for immunoglobulin $\mathrm{G}(\mathrm{IgG})$ antibody response. H. pylori antigen was investigated in the stool specimens of children only.

RESULTS: The participants were divided into two groups: Group 1 consisted of the 40 patients in whom H. pylori infection was demonstrated via endoscopy, their spouses and their children. Group 2 included the remaining 10 patients who underwent endoscopy revealing negative results for $H$. pylori, their spouses and their children. IgG antibodies were present in all of the index parents, $95 \%$ of their spouses and $93 \%$ of their children in group 1; 13 of the children (9\%) were also positive for $\mathrm{H}$. pylori stool antigen ( $\mathrm{HpSA}$ ). However, lgG antibodies were present in only 2 of the 10 index parents in group 2. One of their spouses and one of their children had a positive antibody response. All of their children had negative stool antigen test results. CONCLUSION: H. pylori infections exhibit intrafamilial clustering. Parental infection, age $\geq 7$ years and having three or more siblings are the major risk factors for $\mathrm{H}$. pylori infection in children.
\end{abstract}

\section{INTRODUCTION}

Helicobacter pylori (H. pylori) is the causative agent of peptic ulcer disease and chronic gastritis. It also underlies gastric mucosa-associated lymphoid tissue lymphoma and gastric cancer. The estimated prevalence is almost 70\% in developing countries, and $30-40 \%$ in the United States and other industrialized countries. ${ }^{1}$ In a recent study conducted in Turkey, the prevalence of $H$. pylori infection was reported to be $82.5 \%$ in the adult population. ${ }^{2}$ In developing countries, it is markedly more prevalent at younger ages than it is in developed countries. ${ }^{3}$

Contact with $H$. pylori occurs usually during the first decade of life. Helicobacter seropositivity has been found to increase with age. ${ }^{4}$ It has been reported that more than $30 \%$ of subjects acquired infection before the teenage period. ${ }^{5}$ Ertem et al. investigated the age-related prevalence of $H$. pylori infection in a group of healthy children. They found that one in five of the children became infected before reaching four years of age and that one in two of the children aged under 11 years was infected. ${ }^{6}$ Transmission is most likely to occur person-to-person, and through fecaloral and oral-oral routes. Low socioeconomic status, poor environmental conditions and living in a crowded house have all been correlated with higher prevalence rates. Better hygiene practices and less household overcrowding have contributed to the decline in prevalence over the last decade. ${ }^{7}$

There are several invasive and noninvasive methods for diagnosing $H$. pylori infection. ${ }^{8,9}$ Specific endoscopic findings, the rapid urease test (RUT), histological assessment and gastric tissue cultures all contribute towards making an accurate diagnosis. Molecular methods may be used to prove the presence of $H$. pylori. Noninvasive methods include the urea breath test (UBT), serological tests and stool antigen testing. ${ }^{10,11}$ Detection of $H$. pylori antigen in stools provides evidence of active infection. This has been found to be highly concordant with the 13 -carbon urea breath test $\left({ }^{13} \mathrm{C}\right.$-UBT $) .{ }^{12}$ The stool antigen test is useful for primary diagnosis as well as for assessment of eradication following therapy. ${ }^{13}$

In this study, we determined the $H$. pylori status of family members, to reveal intrafamilial concurrent infection. 


\section{METHODS}

\section{Study design, setting and ethics}

This was a cross-sectional analytical study, conducted in a tertiary care hospital in Istanbul in Turkey. The study was approved by the institution's Internal Review Board (18/12/2012-174). The procedures followed were in accordance with the ethical standards of the Helsinki Declaration and its revisions. Informed consents were obtained for participation in the study.

\section{Patient population}

All adult consecutive patients with gastroduodenal symptoms who underwent gastroscopy were recruited for this study because this procedure provided a definitive diagnosis of $H$. pylori infection in the index case. These patients were enrolled in the study provided that their spouses and children also agreed to enter the study.

\section{Investigations for H. pylori}

The presence of $H$. pylori was determined using RUT (CLOtest) and gastric histological evaluations on biopsy specimens collected by means of endoscopy. Blood samples were drawn from all patients, their spouses and children. Serum samples were stored at $-20{ }^{\circ} \mathrm{C}$ and were assayed for anti-Helicobacter immunoglobulin $\mathrm{G}$ (IgG) antibodies (anti-Hp) using a micro enzyme-linked immunosorbent assay (ELISA) (Premier $H$. pylori, Meridian Diagnostics, Inc., Ohio, USA). The assays were performed in accordance with the manufacturer's instructions. Stool samples were obtained only from the children and were frozen at $-20{ }^{\circ} \mathrm{C}$. H. pylori antigen was determined from the stool specimens using the Premier Platinum $H$. pylori stool antigen (HpSA) enzyme immunoassay (Meridian Diagnostics, Inc., Ohio, USA) as recommended by the manufacturer. Almost all of them were collected in the hospital. Only a few samples were obtained at home, and these were transferred in cold packs.

\section{Statistics}

The data were analyzed using the Statistical Package for the Social Sciences (SPSS) statistical software (SPSS Inc., Chicago, IL, USA). The chi-square test and Fisher's exact test were used. $\mathrm{P}<0.05$ was considered statistically significant.

\section{RESULTS}

Fifty adult patients who underwent gastroscopy (index parents), their spouses $(n=50)$ and their children $(n=159)$ were enrolled in the study. Two groups were set up based on the infection status of the index parents: Group 1 consisted of the 40 patients with documented H. pylori infection (both RUT and histological evaluations revealing positive results), along with their spouses and children. Group 2 included the remaining 10 patients who underwent endoscopy that did not confirm the presence of $H$. pylori infection, along with their spouses and children. The demographic characteristics of the sample are summarized in Table 1.

The index parents in group 1 were all seropositive. Anti-Hp IgG was found in 38 of their spouses $(n=40)$ and 130 of their children $(\mathrm{n}=140)$. Stool antigens were detected in only 13 of these children, who were all seropositive. In contrast, anti-Hp was demonstrated in only two of the 10 index parents in group 2; one of their spouses $(\mathrm{n}=10)$ and one of their children $(\mathrm{n}=19)$ also had IgG antibodies. Stool testing for $H$. pylori antigen revealed negative results in all of the children in group 2 (Table 2 ).

Table 1. Demographic characteristics of the sample

\begin{tabular}{|c|c|c|c|c|c|}
\hline & \multirow[b]{2}{*}{$\mathbf{n}$} & \multicolumn{2}{|c|}{ Age (years) } & \multicolumn{2}{|c|}{ Gender n (\%) } \\
\hline & & $\begin{array}{c}\text { Mean } \pm \\
\text { SD }\end{array}$ & $\begin{array}{c}\text { Age } \\
\text { range }\end{array}$ & Female & Male \\
\hline \multicolumn{6}{|l|}{ Group 1* } \\
\hline Parents & 80 & $36.4 \pm 0.6$ & $25-51$ & $40(50)$ & $40(50)$ \\
\hline Children & 140 & $7.7 \pm 0.2$ & $1.5-14$ & $73(52.1)$ & 67 (47.9) \\
\hline \multicolumn{6}{|l|}{ Group 2** } \\
\hline Parents & 20 & $34.8 \pm 0.9$ & $29-44$ & $10(50)$ & $10(50)$ \\
\hline Children & 19 & $4.4 \pm 0.3$ & $2-6$ & $8(42.1)$ & $11(57.9)$ \\
\hline Infected parents & 81 & $36.4 \pm 0.6$ & $25-51$ & $41(50.6)$ & $40(49.4)$ \\
\hline $\begin{array}{l}\text { Non-infected } \\
\text { parents }\end{array}$ & 19 & $34.8 \pm 0.9$ & $29-44$ & $9(47.4)$ & $10(52.6)$ \\
\hline Infected children & 131 & $7.9 \pm 0.3$ & $2-14$ & $71(54.2)$ & $60(45.8)$ \\
\hline $\begin{array}{l}\text { Non-infected } \\
\text { children }\end{array}$ & 28 & $4.5 \pm 0.2$ & $2-6$ & $10(35.7)$ & $18(64.3)$ \\
\hline \multicolumn{6}{|c|}{ Total study population } \\
\hline Parents & 100 & $36 \pm 0.5$ & $25-51$ & $50(50)$ & $50(50)$ \\
\hline Children & 159 & $7.3 \pm 0.2$ & $1.5-14$ & $81(50.9)$ & 78 (49.1) \\
\hline
\end{tabular}

SD $=$ standard deviation. ${ }^{*}$ Group 1 included the 40 index parents with documented $H$. pylori infection, their spouses and their children; ${ }^{* *} G$ roup 2 consisted of the 10 index parents who underwent endoscopy revealing negative results for $H$. pylori, their spouses and their children.

Table 2. Presence of H. pylori (Hp) immunoglobulin G (lgG) antibodies and stool antigen in the family members in relation to the $H$. pylori status of the index parent who underwent endoscopy for gastroduodenal symptoms

\begin{tabular}{|c|c|c|c|c|c|}
\hline & \multicolumn{2}{|c|}{ Group 1} & \multicolumn{2}{|c|}{ Group 2} & \multirow{2}{*}{$\mathbf{P}$} \\
\hline & $n$ & $\%$ & $n$ & $\%$ & \\
\hline \multicolumn{6}{|c|}{ Anti-Hp, index parent $(n=50)$} \\
\hline+ & 40 & 80 & 2 & 4 & \multirow{2}{*}{$<0.01$} \\
\hline- & 0 & 0 & 8 & 16 & \\
\hline \multicolumn{6}{|c|}{ Anti-Hp, spouses $(n=50)$} \\
\hline+ & 38 & 76 & 1 & 2 & \multirow{2}{*}{$<0.01$} \\
\hline- & 2 & 4 & 9 & 18 & \\
\hline \multicolumn{6}{|c|}{ Anti-Hp, children $(n=159)$} \\
\hline+ & 130 & 82 & 1 & 1 & \multirow{2}{*}{$<0.01$} \\
\hline- & 10 & 6 & 18 & 11 & \\
\hline \multicolumn{6}{|c|}{ HpSA, children $(n=159)$} \\
\hline+ & 13 & 8 & 0 & 0 & \multirow{2}{*}{$>0.05$} \\
\hline- & 127 & 80 & 19 & 12 & \\
\hline
\end{tabular}

HpSA $=$ H. pylori stool antigen. 
The children were evaluated for the risk factors of $H$. pylori infection. The risk of $H$. pylori infection was higher if both parents were infected and with increasing age among the children and greater numbers of siblings (Table 3). Children with positive test results (serological tests and/or positive stool antigen test) were asked about any symptoms of $H$. pylori infection (abdominal pain, dyspeptic signs and gastrointestinal bleeding). All of them were symptom- free.

\section{DISCUSSION}

Transmission of $H$. pylori from infected family contacts has become a subject of research through observations of infection in more than one family member. ${ }^{14-15}$ These studies have differed regarding their study designs (longitudinal or cross-sectional) and study populations (community-based or focusing on the families of $H$. pylori-positive patients). Most of the studies have been carried out either on families randomly selected from the general population or on the family members of children in certain age groups. On the other hand, some studies have approached this topic from the starting point of $H$. pylori-positive patients or patients with gastroduodenal symptoms and have then investigated their families. The present study was conducted among patients who had been referred to an adult gastroenterology clinic, and we subsequently assessed the infection status of their family members.

Various diagnostic tests have been used in research exploring the intrafamilial transmission of $H$. pylori. These tests have comprised anti-Hp, UBT, HpSA and RUT, along with molecular methods such as the polymerase chain reaction (PCR). ${ }^{16-24}$ In our study, the infection status of the index parents was definitively determined by means of RUT and histological evaluations. The spouses and children were tested via serological tests, while a stool antigen kit was also provided for the children.

The most important finding from this study was the high seropositivity observed among the children $(82.4 \%)$. The previously reported local seropositivity rates were $33 \%, 49.5 \%$ and $43.9 \%$ respectively. ${ }^{5,6,14}$ The considerably high level of seropositivity found here can be attributed to the fact that $93.9 \%$ of those children had both parents infected with $H$. pylori who had been suffering gastroduodenal symptoms. This increases the chance of transmission. Lower rates might have been observed in community-based studies.

The key role of parents in transmitting $H$. pylori to their children has been shown in various population-based studies. ${ }^{14-21}$ Dominici et al. assessed the infection rate of children in relation to their parents' infection status, using IgG antibodies. They reported that children whose parents were both seropositive had double the risk of being infected, compared with those whose parents were both seronegative. ${ }^{15}$ In another study, the infection status was determined using UBT among children and salivary IgG antibodies among their parents. It was concluded that infected parents, especially mothers, played a key role in the transmission of H. pylori to their children. ${ }^{16}$

Weyermann et al. conducted a prospective birth cohort study to investigate the acquisition of $H$. pylori infection in early childhood and to clarify the role of parental infection status in the transmission of $H$. pylori to children. Mothers who gave birth to a healthy child, their partners and their other children were included in the study. The presence of active infection of the mothers with $H$. pylori was determined using UBT. The infection statuses of the fathers at the beginning and of their children at the ages of one, two and three years were determined by means of HpSA. These authors claimed that an infected mother was likely to be the main source for $H$. pylori infection among their children. Kissing, shared use of spoons, cleaning pacifiers (dummies) or teats of feeding bottles in the mouth and sharing a bed may facilitate its spread. ${ }^{17}$

Evidence of mother-child transmission of infection was also reported in an article by Escobar and Kawakami. ${ }^{18}$ Nahar et al. screened 55 families for $H$. pylori using a stool antigen test. Those who tested positive were further evaluated through culturing biopsy material or gastric juice. These authors then performed PCR-based random amplified polymorphic deoxyribonucleic acid (DNA) (RAPD) fingerprinting to explore the genetic diversity of H. pylori within families. They observed shared genotypes in the paired strains from mothers and children and concluded that vertical transmission was the most probable route of transmission. ${ }^{19}$

Table 3. Risk factors for H. pylori (Hp) infection in children. $H$. pylori infection was determined through a positive test result for either anti-Hp or $\mathrm{H}$. pylori stool antigen (HpSA)

\begin{tabular}{|c|c|c|c|c|}
\hline & $\begin{array}{c}\text { Children } \\
\text { with H. pylori } \\
\text { infection } \\
(n=131)\end{array}$ & $\begin{array}{l}\text { Children } \\
\text { without } \\
\text { H. pylori } \\
\text { infection } \\
(\mathrm{n}=28)\end{array}$ & OR & $95 \% \mathrm{Cl}$ \\
\hline \multicolumn{5}{|c|}{ Infection status of the parents } \\
\hline $\begin{array}{l}\text { Both parents } \\
\text { infected } \\
\text { Only one or no } \\
\text { parents infected }\end{array}$ & 123 & 25 & 128.1 & $\begin{array}{l}31.8- \\
516.9\end{array}$ \\
\hline \multicolumn{5}{|c|}{ Age of children (years) } \\
\hline $\begin{array}{l}\text { Age } \geq 7 \\
\text { Age }<7\end{array}$ & $\begin{array}{l}83 \\
48\end{array}$ & $\begin{array}{l}12 \\
16\end{array}$ & 2.3 & $1.0-5.3$ \\
\hline \multicolumn{5}{|l|}{ Sex of children } \\
\hline $\begin{array}{l}\text { Girl } \\
\text { Boy }\end{array}$ & $\begin{array}{l}61 \\
70\end{array}$ & $\begin{array}{l}14 \\
14\end{array}$ & 0.9 & $0.4-2.0$ \\
\hline \multicolumn{5}{|l|}{ Number of siblings } \\
\hline $\begin{array}{l}\geq 3 \\
<3\end{array}$ & $\begin{array}{c}106 \\
25\end{array}$ & $\begin{array}{c}1 \\
27\end{array}$ & 114.5 & $\begin{array}{l}14.8- \\
883.0\end{array}$ \\
\hline
\end{tabular}

$\mathrm{OR}=$ odds ratio; $\mathrm{Cl}=$ confidence interval. 
Early diagnosis and prompt treatment of patients might prevent the spread of infection to spouses and children. In the present study, we observed that parental infection was a risk factor for children. However, the mothers' role in the transmission could not be documented, since the proportions of infected mothers and fathers among the infected parents were not significantly different and both spouses were infected in most cases.

Several studies on intrafamilial transmission have been conducted among the parents and siblings of children who either had been referred due to gastroduodenal symptoms or had previously been found to present $H$. pylori-positive status. Drum et al. demonstrated that parents of $H$. pylori-positive children were more likely to have a positive serological response than were the comparably-aged parents of noncolonized children, thus indicating the existence of intrafamilial clustering of $H$. pylori infection..$^{22}$ In another study, $H$. pylori infection was investigated by means of upper gastrointestinal endoscopy and UBT in 100 children with upper gastrointestinal symptoms. UBT was performed on all family members of each index patient. The prevalence of $H$. pylori infection was significantly higher among the families of infected children. ${ }^{23}$ After analyzing 35 children with $H$. pylori gastritis and their family members, Yokota et al. concluded that intrafamilial infection was the dominant transmission route. ${ }^{24}$

All of the above studies focused on index pediatric patients. Our study differed from these through focusing on parents with gastroduodenal symptoms and concentrating on the infection status of their family members. We demonstrated that among the 126 children whose parents were both infected, 123 had a positive test result for either anti-Hp or HpSA. On the other hand, when the parents were not infected, their children were not infected either (Table 3 ). This reflects exact clustering of the infection in the family, thus suggesting that close personal contact facilitated transmission. These families belonged to a middle-class socioeconomic group, and there seemed to be no other risk factor attributable to their living conditions. All of their homes had a water supply from the city and were connected to the sewer system.

There have been reports mentioning higher prevalence of infection among spouses. ${ }^{25-28}$ Brenner et al. assessed the clustering of H. pylori infection among healthy couples. Active infection was measured by means of the urea breath test and HpSA. Their results supported the hypothesis that spouse-to-spouse transmission had a major role in $H$. pylori infection. ${ }^{29}$ However, several years after that report, the same researchers assessed clustering of $H$. pylori infections in both high and low-prevalence population subgroups. They stated that spouse-to-spouse transmission of infection was unlikely to be of relevance in low-prevalence population groups, although clustering of infection was observed in high-prevalence population groups. ${ }^{30}$
Horizontal transmission of $H$. pylori may play an important role in developing countries. However, improved sanitation and quality of life have markedly reduced the risk in developed countries, which has thus enhanced the role of intimate contact in intrafamilial infection. In the present study, we observed seropositivity in 38 spouses of the $40 \mathrm{H}$. pylori-positive index patients (95\%). On the other hand, only one out of the $10 \mathrm{H}$. pylori-negative index patients had a seropositive spouse.

Children play a role in spreading H. pylori. Infection may be transmitted among siblings. We documented that sibship size was a risk factor (Table 3). 99\% of the children were infected when the number of siblings was $\geq 3$, whereas $48 \%$ were infected when the number of siblings was $<3$. The role of siblings in the transmission of infection has previously been reported. ${ }^{23,31-33}$ Infection among siblings may be of more relevance in high-prevalence countries. Transmission probably occurs in early childhood, from older to younger siblings. ${ }^{31,32}$

The prevalence of infection among the children was quite high, with an overall seropositivity rate of $82 \%$. However, only 13 children who were seropositive were also positive for HpSA. This ratio (8\%) was unexpectedly low. The HpSA test has been found to be a reliable method for diagnosing and following up $H$. pylori infection. It is considered useful for screening and monitoring. ${ }^{34}$ In order to perform diagnostic tests other than serological tests, waiting two weeks after the end of proton pomp inhibitor therapy and four weeks after the end of antibiotic therapy is recommended. ${ }^{3,34}$ Prior antibiotic therapy or spontaneous elimination of $H$. pylori infection ${ }^{35}$ may explain the high seropositivity rate ( $82 \%$ of the children in the present study) alongside the low positivity rate for stool antigen (8\%) in those children. Constipation, presumably due to degradation of $H$. pylori antigens, may also contribute to this result.

H. pylori-positive patients pose a risk of transmission of infection to their other family members. We observed that if one of the parents was infected with $H$. pylori, the risk of infection was significantly higher for their spouses and children. When both parents were infected, their children had a higher rate of infection than did children with only one or no parents infected. Crowded living conditions (number of siblings $>3$ ) increased the risk. These findings support the notion that transmission occurs from person to person, through close contact, and that it occurs during childhood.

One limitation of the present study is that we did not prove that a single $H$. pylori strain caused the intrafamilial clustering in each family. Nonetheless, presence of a single strain would not constitute sufficient evidence of person-to-person transmission. The shared strain indicates only a common source, which may be an environmental factor as well. However, our patients had access to a water supply from the city and adequate sanitation facilities.

The joint European Society for Paediatric Gastroenterology Hepatology and Nutrition (ESPGHAN)/North American Society 
for Pediatric Gastroenterology, Hepatology and Nutrition (NASPGHAN) guidelines do not recommend starting treatment based on screening for the presence of $H$. pylori infection by means of a noninvasive test applied to children (recommendation 2c). Instead, they recommend testing for $H$. pylori among children with gastric or duodenal peptic ulcer disease (recommendation 3). ${ }^{34}$

Presence of $H$. pylori is a risk factor for duodenal ulcers in children. ${ }^{36}$ Considering the fact that it is highly transmitted within family settings, presence of parental $H$. pylori infection should prompt physicians to ask children about any gastroduodenal symptoms compatible with peptic ulcer disease. Children with positive symptoms should be further evaluated for peptic ulcer disease.

There is a need to determine which symptoms should be interpreted as indicative of the presence of peptic ulcer disease. Hernandez et al. performed upper gastrointestinal endoscopy due to suspicion of peptic disease when at least one of the following manifestations was observed: hematemesis; chronic epigastric pain or nocturnal awakening with abdominal pain; chronic vomiting associated with eating; suspected peptic ulcer disease relapse; and recurrent abdominal pain in children with a first-degree relative with peptic ulcer disease. H. pylori infection was confirmed in $56.1 \%$ of the children and duodenal ulcer was diagnosed in 32 patients (13.5\%). ${ }^{37}$ Guariso et al. declared that upper gastrointestinal endoscopy was appropriate for cases with a family history of peptic ulcer and/or $H$. pylori infection, in individuals older than 10 years of age, with dyspeptic symptoms persisting for more than six months that were severe enough to affect activities of daily living. ${ }^{38}$ Thus, analysis on the cost-effectiveness of further investigation of the patients with gastroduodenal symptoms compatible with peptic ulcer disease and a family history of $H$. pylori infection could form the subject of a further study.

\section{CONCLUSION}

We observed concurrent intrafamilial $H$. pylori infection. It may have been transmitted within the family. Parental infection, age $\geq 7$ years and having three or more siblings are the major risk factors for $H$. pylori infection in children. Infection of parents puts children at risk. The risk increases with age and number of siblings.

\section{REFERENCES}

1. Barzilay EJ, Fagan RP. Helicobacter pylori. In: Brunette GW, editor. CDC Health Information for International Travel 2014: The Yellow Book (CDC Health Information for International Travel: The Yellow Book). New York: Oxford University Press; 2014. p. 80-1.

2. Ozaydın N, Turkyılmaz SA, Cali S. Prevalence and risk factors of helicobacter pylori in Turkey: a nationally-representative, cross-sectional, screening with 13C-Urea breath test. BMC Public Health. 2013;13:1215. doi: 10.1186/1471-2458-13-1215.
3. World Gastroenterology Organisation. World Gastroenterology Organisation Global Guideline: Helicobacter pylori in developing countries. J Clin Gastroenterol. 2011;45:(5):383-8. doi: 10.1097/ MCG.0b013e31820fb8f6.

4. Miranda AC, Machado RS, Silva EM, Kawakami E. Seroprevalence of Helicobacter pylori infection among children of low socioeconomic level in São Paulo. Sao Paulo Med J. 2010;128(4):187-91. PMID: 21120427.

5. Us D, Hascelik G. Seroprevalence of Helicobacter pylori infection in an Asymptomatic Turkish population. J Infect. 1998;37(2):48-50. PMID: 9821089.

6. Ertem D, Harmancı H, Pehlivanoğlu E. Helicobacter pylori infection in Turkish preschool and school children: role of socioeconomic factors and breast feeding. Turk J Pediatr. 2003;45(2):114-22. PMID: 12921297.

7. Eusebi LH, Zagari RM, Bazzoli F. Epidemiology of Helicobacter pylori infection. Helicobacter. 2014;19 Suppl. 1:1-5. doi: 10.1111/hel.12165.

8. Mégraud F, Bessède E, Lehours P. Diagnosis of Helicobacter pylori infection. Helicobacter. 2014;19 Suppl. 1:6-10. doi: 10.1111/hel.12161.

9. Crowley E, Bourke B, Hussey S. How to use Helicobacter pylori testing in paediatric practice. Arch Dis Child Educ Pract Ed. 2013;98(1):18-25. doi: 10.1136/archdischild-2012-301642.

10. Gomes AT, Coelho LK, Secaf M, et al. Accuracy of the 14C-urea breath test for the diagnosis of Helicobacter pylori. Sao Paulo Med J. 2002;120(3):6871. PMID: 12163895.

11. Ogata SK, Kawakami E, Patrício FR, Pedroso MZ, Santos AM. Evaluation of invasive and non-invasive methods for the diagnosis of Helicobacter pylori infection in symptomatic children and adolescents. Sao Paulo Med J. 2001;119(2):67-71. PMID: 11276169

12. de Carvalho Costa Cardinali L, Rocha GA, Rocha AM, et al. Evaluation of [13C]urea breath test and Helicobacter pylori stool antigen test for diagnosis of $\mathrm{H}$. pylori infection in children from a developing country. J Clin Microbiol. 2003;41(7):3334-5. PMID: 12843086.

13. Shimoyama T. Stool antigen tests for the management of Helicobacter pylori infection. World J Gastroenterol. 2013;19(45):8188-91. doi: 10.3748/ wjg.v19.145.8188.

14. Yilmaz E, Doğan Y, Gürgöze MK, Unal S. Seroprevalence of Helicobacter pylori infection among children and their parents in eastern Turkey. J Paediatr Child Health. 2002;38(2):183-6. PMID: 12031003

15. Dominici P, Bellentani S, Di Biase AR, et al. Familial clustering of Helicobacter pylori infection: population based study. BMJ. 1999;319(7209):537-40. PMID: 10463891.

16. Rothenbacher D, Winkler M, GonserT, Adler G, Brenner H. Role of infected parents in transmission of helicobacter pylori to their children. Pediatr Infect Dis J. 2002;21(7):674-9. doi: 10.1097/01.inf.0000021081.69738.42.

17. Weyermann M, Adler G, Brenner H, Rothenbacher D. The mother as source of Helicobacter pylori infection. Epidemiology. 2006;17(3):332-4. doi: 10.1097/01.ede.0000201257.31155.a0.

18. Escobar ML, Kawakami E. Evidence of mother-child transmission of Helicobacter pylori infection. Arq Gastroenterol. 2004;41(4):239-44. doi: /S0004-28032004000400008. 
19. Nahar S, Kibria KM, Hossain ME, et al. Evidence of intra-familial transmission of Helicobacter pylori by PCR-based RAPD fingerprinting in Bangladesh. Eur J Clin Microbiol Infect Dis. 2009;28(7):767-73. doi: 10.1007/s10096-008-0699-8.

20. Nguyen VB, Nguyen GK, Phung DC, et al. Intra-familial transmission of Helicobacter pylori infection in children of households with multiple generations in Vietnam. Eur J Epidemiol. 2006;21 (6):459-63. doi: 10.1007/ s10654-006-9016-y.

21. Ito LS, Oba-Shinjo SM, Shinjo SK, et al. Community-based familial study of Helicobacter pylori infection among healthy Japanese Brazilians. Gastric Cancer. 2006;9(3):208-16. doi: 10.1007/s10120-006-0384-5.

22. Drumm B, Perez-Perez GI, Blaser MJ, Sherman PM. Intrafamilial clustering of Helicobacter pylori infection. N Engl J Med. 1990;322(6):359-63. doi: 10.1056/NEJM199002083220603.

23. Roma E, Panayiotou J, Pachoula J, et al. Intrafamilial spread of Helicobacter pylori infection in Greece. J Clin Gastroenterol. 2009;43(8):711-5. doi: 10.1097/MCG.0b013e318192fd8a.

24. Yokota SI, Konno M, Fujiwara SI, et al. Intrafamilial, preferentially mother-to-child and intraspousal, Helicobacter pylori infection in Japan determined by multilocus sequence typing and random amplified polymorphic DNA fingerprinting. Helicobacter. 2015,20(5):334-42. doi: 10.1111/hel.12217.

25. Georgopoulos SD, Mentis AF, Spiliadis CA, et al. Helicobacter pylori infection in spouses of patients with duodenal ulcers and comparison of ribosomal RNA gene patterns. Gut. 1996;39(5):634-8. PMID: 9026475.

26. Parente F, Maconi G, Sangaletti O, et al. Prevalence of Helicobacter pylori infection and related gastroduodenal lesions in spouses of Helicobacter pylori positive patients with duodenal ulcer. Gut. 1996;39(5):629-33. PMID: 9026474

27. Singh V, Trikha B, Vaiphei K, et al. Helicobacter pylori: evidence for spouseto-spouse transmission. J Gastroenterol Hepatol. 1999;14(6):519-22. PMID: 10385058.

28. Osaki T, Konno M, Yonezawa $\mathrm{H}$, et al. Analysis of intra-familial transmission of Helicobacter pylori in Japanese families. J Med Microbiol. 2015;64(Pt 1):67-73. doi: 10.1099/jmm.0.080507-0.

29. Brenner H, Rothenbacher D, Bode G, Dieudonné P, Adler G. Active infection with Helicobacter pylori in healthy couples. Epidemiol Infect. 1999;122(1):91-5. PMID: 10098790.

30. Brenner H, Weyermann M, Rothenbacher D. Clustering of Helicobacter pylori infection in couples: differences between high- and lowprevalence population groups. Ann Epidemiol. 2006;16(7):516-20. doi: 10.1016/j.annepidem.2005.09.009.

31. Goodman KJ, Correa P. Transmission of Helicobacter pylori among siblings. Lancet. 2000;355(9201):358-62. PMID: 10665555.

32. Cervantes DT, Fischbach LA, Goodman KJ, et al. Exposure to Helicobacter pylori-positive siblings and persistence of Helicobacter pylori infection in early childhood. Pediatr Gastroenterol Nutr. 2010;50(5):481-5. doi: 10.1097/MPG.0b013e3181 bab2ee.

33. Fialho $A M$, Braga $A B$, Braga Neto MB, et al. Younger siblings play a major role in Helicobacter pylori transmission among children from a low-income community in the Northeast of Brazil. Helicobacter. 2010;15(6):491-6. doi: 10.1111/j.1523-5378.2010.00791.x.

34. Jones NL, Koletzko S, Goodman K, et al. Joint ESPGHAN/NASPGHAN Guidelines for the management of Helicobacter pylori in children and adolescents (Update 2016). J Pediatr Gastroenterol Nutr. 2017;64(6):9911003. doi: 10.1097/MPG.0000000000001594.

35. Miranda AC, Machado RS, Kawakami E. Spontaneous elimination of Helicobacter pylori infection in a cohort of asymptomatic school children by enzyme-linked immunosorbent assay polyclonal antigen in stool. J Clin Gastroenterol. 2008;42(2):143-6. doi: 10.1097/ MCG.0b013e318032389e.

36. Bontems $\mathrm{P}$, Kalach $\mathrm{N}$, Vanderpas J, et al. Helicobacter pylori infection in European children with gastro-duodenal ulcers and erosions. Pediatr Infect Dis J. 2013;32(12):1324-9. doi: 10.1097/INF.0000000000000005.

37. Hernández C, Serrano C, Einisman H, et al. Peptic ulcer disease in Helicobacter pylori-infected children: Clinical findings and mucosal immune response. J Pediatr Gastroenterol Nutr. 2014;59(6):773-8. doi: 10.1097/MPG.0000000000000500.

38. Guariso G, Meneghel A, Dalla Pozza LV, et al. Indications to upper gastrointestinal endoscopy in children with dyspepsia. J Pediatr Gastroenterol Nutr. 2010;50(5):493-9. doi: 10.1097/ MPG.0b013e3181bb3362.

\section{Conflict of interest: None}

Sources of funding: None

Date of first submission: March 8, 2017

Last received: December 23, 2017

Accepted: December 31, 2017

\section{Address for correspondence:}

Ayse Palanduz

Department of Family Medicine, Istanbul University, Istanbul Faculty of Medicine

Millet Cad., 34093 Fatih, Istanbul — Turkey

Tel. 905322538425

E-mail:apalanduz@istanbul.edu.tr 